\title{
What Needs Tell Us about User Experience
}

\author{
Annika Wiklund-Engblom ${ }^{1}$, Marc Hassenzahl ${ }^{2,1}$, Anette Bengs ${ }^{1}$, \\ and Susanne Sperring ${ }^{1}$
}

\author{
${ }^{1}$ MediaCity, Åbo Akademi University, Box 311, 65101 Vaasa, Finland \\ ${ }^{2}$ Folkwang University, Campus Universitat Duisburg-Essen, Universitatstrasse 12, 45141 \\ Essen, Germany \\ \{Annika.Wiklund-Engblom, Anette.Bengs, Susanne.Sperring\} @abo.fi, \\ Marc.Hassenzahl@Folkwang-Hochschule.de
}

\begin{abstract}
The present study explores the sources and consequences of fulfilling six fundamental human needs, namely Autonomy, Relatedness, Competence, Stimulation, Influence, and Security, through using interactive products and media. Each need refers to a distinct set of issues, such as according product attributes (e.g., "flexibility") and experiential consequences (e.g., "freedom of choice"). Besides the need-specific content, which helps to characterize and differentiate user experiences, the study reveals the close relation between needs and according product attributes as their mirror images.
\end{abstract}

Keywords: User Experience, Fundamental Needs, Technology and Media Interaction.

\section{Introduction}

User experience (UX) as a concept recently gained momentum in the field of HumanComputer Interaction (HCI) [e.g., 5]. Despite the lack of an official definition and some debates about the actual scope of UX [e.g., 7], there is a common understanding that UX is holistic - it emphasizes the totality of emotion, motivation, and action in a given physical and social context - and that it is subjective - focusing on the "felt experiences" [8] rather than product attributes.

Battarbee [1] distinguishes person-centred frameworks, focusing on human needs and/or the relationship people have with products from more product-centred, focusing on qualities of the design, i.e. product attributes. Although, many different definitions and models of UX exist, there seems to be some agreement that UX complements a traditional, usability-oriented approach by going beyond the technical or task-related into human emotions and needs, that is, from the product-centred to the person-centred. However, this does not imply that usability is not important anymore. It rather highlights that UX as a consequence of both, product-centred aspects, such as functionality and aesthetics, as well as person-centred aspects, such as personal motivation and needs [10].

Personal motivations and needs received relatively little attention in $\mathrm{HCI}$, but current research on UX seeks to close that gap. A recent definition, for example, describes UX as "a momentary, primarily evaluative feeling (good-bad) while 
interacting with a product or service. [...] Good UX is the consequence of fulfilling the human needs for autonomy, competency, stimulation (self-oriented), relatedness, and popularity (others-oriented) through interacting with the product or service. To do so, products and services need a balance between pragmatic (e.g., usability) and hedonic quality (e.g., novelty)" [3]. Here, underlying, general psychological needs "beyond the instrumental" [5] play a major role as a source of positive emotions (e.g., pleasure, enjoyment) and well-being and as motivators of action [see also 4 and 2].

One research instrument from psychology that specifically targets fundamental needs is a Needs Schedule developed by Sheldon, Elliot, Kim, and Kasser [9]. This questionnaire "measures" ten general fundamental needs. These were used on several occasions to let people describe their experiences with technology and media [3; unpublished studies]. It summarizes and builds upon a variety of prominent theories, such as Ryan and Deci's Self-Determination Theory, Maslow's theory of personality, Epstein's cognitive-experiential self-theory, and Derber's lay theory of human needs.

The present study explores the sources and consequences of the fulfilment of six out of the ten Sheldon's et al. fundamental needs, namely Autonomy, Relatedness, Competence, Stimulation, Influence, and Security. Instead of using a questionnaire, however, participants answered open-ended questions (in writing) on the experience of the fulfilment of each need through using an interactive product and media. Ten people participated in the study. Each wrote about their needs fulfilment through a freely chosen product and media (i.e., 20 descriptions, two from each participant).

\section{Results}

We analyzed the data by the method of meaning condensation [6] of the participant's statements to identify sources of needs fulfilment and its experiential consequences. Table 1 shows an overview of the results organized by respective need.

The experience of autonomy, for example, was related to the opportunity to "be real", i.e. being enabled by a product to be oneself, without caring much for the demands of other social roles, to "express own opinions" and to define one's "integrity". Both are the consequence of the specific functionality of the product or media mentioned by the participant and revolve around the theme of self-identity. More generally, autonomy was connected to the "flexibility" of the product, i.e., the freedom of using or not using it anywhere and anytime. Flexibility can be thought of as more general product attribute, summarizing functionality and other aspects of the products (e.g., mobility, usability). A last source for autonomy was the freedom using whatever product one prefers. The value lies in the free choice per se, which cannot be linked directly to specific functionality or other product attributes. Security - to give a further example - was implied by "reliability" and "familiarity" of the product (and situations) and "social support" enabled through the functionality of the product (see Table 1 for an overview of the needs related experiences and interpretations). 
Table 1. Needs Interpretations Based on Participants' Technology and Media Experiences

\begin{tabular}{|c|c|c|}
\hline Needs & Interpretation & Participants' Experience Descriptions \\
\hline \multirow{5}{*}{ 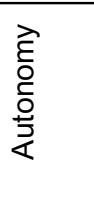 } & Flexibility & "I can listen to it anywhere." [mp3 player] \\
\hline & Integrity & "My phone - integrity" [mobile phone] \\
\hline & Freedom of Choice & "It was a big step to switch from a PC to a Mac." [MacBook] \\
\hline & Express Own Opinions & "I, of course, have my own opinion." [blog] \\
\hline & Be Real & $\begin{array}{l}\text { "Being able to be myself without having to care about my other social } \\
\text { roles." [Facebook] }\end{array}$ \\
\hline \multirow{4}{*}{ 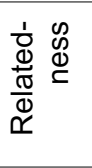 } & Communication & $\begin{array}{l}\text { "Definitely, by keeping in touch with a large group of friends." } \\
\text { [Facebook] }\end{array}$ \\
\hline & Information & "Yes, when there are local news in the paper." [newspaper] \\
\hline & Sharing & "Not the music, but sharing it with others." [music] \\
\hline & Brand/Identity & "I love my Mac = We the Mac-users against PC." [MacBook] \\
\hline \multirow{4}{*}{ 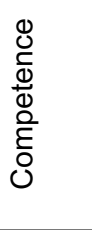 } & Usability & "Everything works naturally and well ..." [MacBook] \\
\hline & Novelty & $\begin{array}{l}\text { "... at first when I found new functions, but not anymore." [mp3 } \\
\text { player] }\end{array}$ \\
\hline & Mastery & $\begin{array}{l}\text { "It gives me a feeling of competence when I find a new radio } \\
\text { channel." [iTunes radio] }\end{array}$ \\
\hline & Knowledge & $\begin{array}{l}\text { "I feel up-to-date about what is happening locally and in the world." } \\
\text { [newspaper] }\end{array}$ \\
\hline \multirow{5}{*}{ 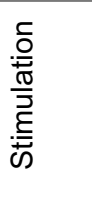 } & Social & "... to have access to various chats simultaneously." [Fring] \\
\hline & Cognitive & $\begin{array}{l}\text { "Yes, to express oneself in cleaver ways and communicate } \\
\text { intelligently with friends provides stimulation." [Facebook] }\end{array}$ \\
\hline & Emotional & "It stimulates on an emotional level." [music] \\
\hline & Existential & "It confirms my existence." [newspaper] \\
\hline & Creativity & "It gives me new ideas." [newspaper] \\
\hline \multirow{3}{*}{ 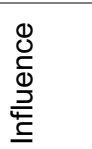 } & Connectedness & $\begin{array}{l}\text { "To be able to reach others and be reached increases the feeling of } \\
\text { influence." [laptop] }\end{array}$ \\
\hline & Communication & "By using it to communicate, influencing others." [mobile phone] \\
\hline & Awareness of Options & "I can influence - if I have the energy to do so." [newspaper] \\
\hline \multirow{4}{*}{ 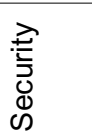 } & Reliability & "I can trust that it always works." [coffee maker] \\
\hline & Satisfaction & "It's a way of winding down at home in the sofa." [TV] \\
\hline & Social Support & "I can call someone. Help is close by if it's needed." [mobile phone] \\
\hline & Familiarity & "Ordinary things in an ordinary environment." [newspaper] \\
\hline
\end{tabular}

\section{Discussion}

This study was a first step in illuminating the issues revolving around the fulfilment of a set of universal human needs through interactive products and media. Besides the insights into the specific topics related to specific needs, such as reliability to security or "being real" to autonomy, at least two notable, more general aspects became apparent. First, issues are quite different depending on the particular need. Thus, designing for a security experience may invoke a completely different set of requirements compared to a stimulation, competence or autonomy experience. In all cases, needs fulfilment is a source of general positive emotions but the presumably soothing, relaxing experience of security will be quite different from the strong, bold, and self-conscious experiences of autonomy - not only phenomenological, but also in the according functional requirements and the product attributes looked for. 
Second, asked about the experience of needs fulfilment through products, participants spontaneously produce person(self)-centred aspects, such as emotional states, feelings, and values, as well as product-centred aspects, such as functionality or products attributes. On one hand, this highlights that people are aware and can articulate the way in which a product or media fulfils their needs. On the other hand, it clarifies the actual nature of product attributes, such as "usable," "reliable," or "flexible." As the name implies, a product attribute is the consequence of an attribution process, which relates an experience to the product and establishes it as the cause of this experience. In other words, reliability is one consequence of security experiences perceived as being caused by the respective product. This implies fewer differences between a product-centred and a person-centred approach as expected [e.g., 1], because attributes are the consequence of needs fulfilment-related experiences - their mirror images.

Universal needs are limited in number, but may still be a promising way to characterize and distinguish different types of experiences. Other than experienceframeworks such as McCarthy and Wright's [8], needs address the content of experiences not only their structure. Where McCarthy and Wright, for example, stop with the observation that experiences have an emotional-motivational and a meaningmaking thread, the needs perspective clarifies where the emotion, motivation, and meaning comes from. By that, it becomes much easier to address experiences in the context of product and media design.

\section{References}

1. Battarbee, K.: Co-Experience: Understanding User Experiences in Social Interaction, Helsinki, Finland. Publication series of the University of Art and Design (2004)

2. Cockton, G.: From Quality in Use to Value In The World. In: CHI 2004 Conf. on Human Factors in Computing Systems. Extended abstracts, pp. 1287-1290. ACM, New York (2004)

3. Hassenzahl, M.: User Experience (UX): Towards an Experiential Perspective on Product Quality [Keynote]. In: The 20th IHM 2008 Conf. (2008)

4. Gaver, W.W., Martin, H.: Alternatives. Exploring Information Appliances through Conceptual Design Proposals. In: CHI 2000 Conf. on Human Factors in Computing, pp. 209216. ACM, Addison-Wesley, NY (2000)

5. Hassenzahl, M., Tractinsky, N.: User Experience - A Research Agenda [Editorial]. Behavior and Information Technology 25, 91-97 (2006)

6. Kvale, S.: Interviews: An Introduction to Qualitative Research Interviewing. SAGE Publications, Thousand Oaks (1996)

7. Law, E., Roto, V., Hassenzahl, M., Vermeeren, A., Korte, J.: Understanding, Scoping And Defining User eXperience: A survey approach. In: CHI 2009 Conf. on Human Factors in Computing Systems, pp. 719-728. ACM, New York (2009)

8. McCarthy, J., Wright, P.C.: Technology as Experience. MIT Press, Cambridge (2004)

9. Sheldon, K.M., Elliot, A.J., Kim, Y., Kasser, T.: What Is Satisfying About Satisfying Needs? Testing 10 Candidate Psychological Needs. J. of Personality 80, 325-339 (2001)

10. Vyas, D., van der Veer, G.C.: Rich Evaluations of Entertainment Experience: Bridging the Interpretational Gap. In: The 13th ECCE 2006, vol. 250, pp. 137-144 (2006) 